\section{Role of high dose IV vitamin C and zinc in coronavirus}

Arooj Fatima, ${ }^{1}$

Muhammad Usman Ali Khan, ${ }^{1}$

Mehkaar Najeeb, ${ }^{2}$

Muhammad Yasoob Ali Khan, ${ }^{3}$

Faiz UI Haq ${ }^{4}$

${ }^{1}$ Department of Pharmacology

University of Health Sciences, Lahore;

${ }^{2}$ Department of Physiology, University of

Health Sciences, Lahore; ${ }^{3}$ Combined

Miltary Hospital, Multan; ${ }^{4}$ Department

of Microbiology, University of Health

Sciences, Lahore, Pakistan

\section{Abstract}

Coronavirus disease 2019 (COVID-19), caused by severe acute respiratory syndrome-related coronavirus 2 (SARS-CoV2 ), is now considered as an ongoing global pandemic. Common symptoms include pyrexia, cough, dyspnea, fatigue, sore throat, and loss of sense of taste and smell. Complications that can result from more severe insult on lung tissue is pneumonia and acute respiratory distress syndrome (ARDS), which can further lead to septic shock. It is also not uncommon to find neurological symptoms in patients suffering from COVID-19. The primary treatment for COVID-19 is symptomatic treatment and supportive care. As there is no known vaccination and antiviral therapy for this disease, there is a desperate need to find an alternative to control and stop the spread of disease. Maintaining adequate micronutrient balance might enhance the immunity and protect from viral infections as well. Vitamin $\mathrm{C}$ and zinc helps in improving symptoms and shortening the duration of the common cold. Vitamin C (L-ascorbic acid) possesses pleiotropic physiological activity. High dose Vitamin $\mathrm{C}$ has shown to be effective against the common flu, rhinovirus, avian virus, chikungunya, Zika, ARDS, and influenza, and there is evidence that supports the protective effect of high dose IV vitamin $\mathrm{C}$ during sepsis-induced ARDS due to COVID-19. Zinc has a profound impact on the replication of viruses. Increasing intracellular zinc concentration along with pyrithione (zinc ionophore) has been shown to impair the replication of several RNA viruses efficiently, including poliovirus, influenza virus and several picornaviruses. A combination of zinc and can also inhibit the replication of SARScoronavirus in cell culture.

\section{Introduction}

In December of 2019 large number of patients were presented to the hospitals in the city of Wuhan in the Hubei province of China. All these patients had symptoms related to pneumonia, and the etiological agent was unknown. Epidemiologically patients were all related to the seafood market of the Wuhan region. ${ }^{1,2}$ This pneumonia causing agent was identified as a novel coronavirus and causes coronavirus disease (COVID-19). ${ }^{3}$ Coronavirus has genetic makeup related to the family of coronaviruses and is related genetically to severe acute respiratory syndrome (SARS) and Middle East respiratory syndrome (MERS). ${ }^{4}$ As compared to SARS caused by coronavirus 1 , patients with COVID-19 can be infectious in the asymptomatic stage during their incubation period. ${ }^{5}$ There are multiple variables of the course of the disease and management that need optimization. ${ }^{5}$ As of 18 June 2020, there are 8,242,999 confirmed cases and 445,535 deaths worldwide. $^{6}$ The COVID-19 pandemic requires a quick response but developing vaccination or antivirals specific to COVID-19 is taking time. ${ }^{7}$ Till now, there are no Food and Drug Administration approved treatments or vaccines for highly pathogenic coronaviruses. ${ }^{8}$ Strategies that could immediately save lives are needed desperately. ${ }^{7}$ Patients with coronavirus presents with pyrexia (85\%), cough $(67.7 \%)$, dyspnea $(18.6 \%)$, sore throat $(13.9 \%)$ and nasal congestion (4.8\%). The complication that can result from more severe insult on lung tissue is acute respiratory distress syndrome (ARDS), which can further lead to septic shock. Apart from these pulmonary symptoms, some patients are found to have neurological symptoms too. A study conducted on 841 patients in a Spanish hospital found that $57.4 \%$ of confirmed COVID-19 patients had neurological symptoms of some sort. $19.6 \%$ of the test population suffered from altered consciousness state, most of which were elderly and in advance stage of the disease. Of the patients who died, $4.1 \%$ had a neurological cause. ${ }^{9}$ Researchers also have isolated novel coronavirus from the cerebrospinal fluid (CSF) of affected patients; however, a case report also points towards viral encephalitis in which CSF contents are found to be within the normal range. Autopsies have revealed brain edema and partial neuron degeneration in eased patients. ${ }^{10,11}$

These complications are responsible for mortality and are contributors to Intensive care Unit (ICU) admission of patients older than 60 years, with smoking, or any other preexisting morbidity. ${ }^{5}$ As there is no spe-
Correspondence: Muhammad Usman Ali

Khan, Department of Pharmacology

University of Health sciences Lahore,

Pakistan.

Tel.: +92.3457495041

E-mail: usman.a.khan415@gmail.com

Key words: COVID-19; SARS-CoV-2; vita$\min \mathrm{C}$; zinc; treatment.

Acknowledgments: we would like to thank to all frontline health care workers that work in frontline of COVID-19.

Contributions: the authors contributed equally.

Conflict of interests: the authors declare no potential conflict of interests.

Received for publication: 5 September 2020. Revision received: 13 November 2020.

Accepted for publication: 14 January 2021.

This work is licensed under a Creative Commons Attribution-NonCommercial 4.0 International License (CC BY-NC 4.0).

${ }^{\circ}$ Copyright: the Author(s), 2021

Licensee PAGEPress, Italy

Geriatric Care 2021; 7:9338

doi:10.4081/gc.2021.9338

cific treatment of this novel coronavirus, there is a desperate need to find an alternative solution to stop and control the spread of this virus. ${ }^{12}$

Literature is emerging that suggests the adjunctive role of vitamin $\mathrm{C}$ in the treatment of viral infection because vitamin $\mathrm{C}$ is found to be virucidal in high doses..$^{13}$

Pneumonia and neurological damage seem to be caused by hyperactive immune cells or cytokine storm. ${ }^{10}$ IV high dose vitamin $C$ could be the beneficial choice and safe during early stages of COVID-19 because it causes immunosuppression at the level of effector cells. ${ }^{14}$ Zinc is an essential trace element that is required for the maintenance and development of innate and acquired immune systems. The combination of zinc and pyrithione (zinc ionophore) can inhibit the replication of a variety of RNA viruses efficiently, including SARS-related coronavirus (SARS-CoV). Therefore, zinc supplement has an effect not only on the symptoms related to COVID-19 but also on COVID-19 itself. ${ }^{12}$

\section{Intravenous vitamin $\mathbf{C}$ and zinc as immune boosters}

Vitamin $\mathrm{C}$ (ascorbic acid) and zinc are essential nutrients that play a vital role in 
the normal functioning and maintenance of human health. Both have profound effects on the growth and differentiation of cells and are required for the operation of the immune system optimally. Inadequacy of vitamin $\mathrm{C}$ or zinc can lead to the weakened immune system with alteration in resistance to infections, impaired growth, and delay in wound healing due to weakened collagenous structures. ${ }^{15}$ Vitamin C, also known as ascorbic acid, is a water-soluble vitamin. Vitamin $\mathrm{C}$ acts as an antioxidant and plays its role in the synthesis of collagen in connective tissue. ${ }^{12}$ There is compelling evidence from animal models of sepsis that intravenous vitamin $\mathrm{C}$ injection increases survival and protects microvascular functions, including blood flow of capillary, microvascular permeability barrier, and arteriolar response to vasodilator and vasoconstrictors. These effects are both persistent and rapid, as vitamin $\mathrm{C}$ accumulates quickly in microvascular endothelial cells, scavenges reactive oxygen species (ROS), and take action through tetrahydrobiopterin to stimulate NO production by endothelial nitric oxide synthase (Table 1). ${ }^{16}$

Vitamin $\mathrm{C}$ is an important micronutrient for humans, with a strong cofactor and antioxidant for a number of gene regulatory and biosynthetic enzymes. Vitamin $\mathrm{C}$ is important in immune defense by supporting several functions of both the adaptive and innate immune system. Vitamin $\mathrm{C}$ act as a cofactor for a number of biosynthetic and gene regulatory monooxygenase and dioxy- genase enzymes. The vitamin has been known long as a cofactor for the prolyl and lysyl hydroxylases required to stabilize the collagen tertiary structure, and also act as a cofactor for the two hydroxylases that is involved in biosynthesis of carnitine, a molecule that play role in generation of metabolic energy using transport of fatty acids into mitochondria. ${ }^{17-19}$

Vitamin $\mathrm{C}$ is also crucial in stimulation of phagocytic cells, such as migration of neutrophils, phagocytosis, microbial killing, generation of ROS, and enhance chemotaxis. It is also desirable for apoptosis and clearance of the expended neutrophils from infection sites by macrophages, thereby avoiding potential tissue damage. ${ }^{17}$

Zinc is a dietary trace mineral and is essential for maintenance and development of immune cells of both the innate and adaptive immune system. Deficiency of zinc can result in dysfunction of cell-mediated and antibody-mediated immunity and increases susceptibility to infectious diseases. Zinc supplement given to zinc-deficient children could reduce measles-related morbidity and mortality caused by lower respiratory tract infections. ${ }^{20}$

\section{Antiviral role of vitamin C}

The inspiration for using IV vitamin $\mathrm{C}$ (IVC) for the treatment of viral infections comes, in part, from the fact that patients with viral infections exhibit deficiency of vitamin $C$. This suggests that the management of viral infections may benefit from vitamin $\mathrm{C}$ supplementation. ${ }^{21}$ According to three human controlled trials, the incidence of pneumonia was significantly lower in vitamin $\mathrm{C}$ treated groups, suggesting that vitamin $\mathrm{C}$ might prevent the occurrence of lower respiratory tract infections under certain conditions..$^{20}$ Vitamin $\mathrm{C}$ is directly virucidal in high doses. It was assumed based on in vitro studies, where very high dose vitamin $\mathrm{C}$ in the presence of iron or copper, presumably through the generation of radical species and hydrogen peroxide, has virucidal activity. ${ }^{22}$ It has been suggested that administration of vitamin $\mathrm{C}$ orally can prevent herpes simplex virus (HSV)-1 reactivation under experimental environment. ${ }^{23}$ Previous reports also showed that IV administration of high-dose vitamin C helped to reduce the pain in patients with post herpetic neuralgia and the treatment of patients with herpes Zoster. ${ }^{24}$

\section{The antiviral role of zinc}

$\mathrm{Zn} 2+$ is needed for the replication of many viruses and has been shown to play a crucial role in viral infections. Zinc status is a critical factor that can influence antiviral immunity, mainly as zinc-deficient populations are often most at risk of acquiring viral diseases such as human immunodeficiency

Table 1. Role of IV vitamin C as an immune booster. ${ }^{16}$

Enhancement of interferon production

Enhancement of phagocytic function

The selective concentration of vitamin $\mathrm{C}$ in white blood cells

Enhancement of cell-mediated immune response

Enhancement of cytokine production by white blood cells

Inhibition of T-lymphocyte apoptosis

Enhancement of nitric oxide production by phagocytes

Enhancement of T-lymphocyte proliferation

Enhancement of B-lymphocyte proliferation

Inhibition of neuraminidase

Enhancement of antibody production and complement activity

Enhancement of natural killer cell activity

Enhancement of prostaglandin formation

Enhancement of cyclic GMP levels in lymphocytes

Enhanced localized generation of hydrogen peroxide

Vitamin $\mathrm{C}$ and hydrogen peroxide can dissolve the protective capsules of some bacteria, such as pneumococci

Detoxification of histamine

Neutralization of the oxidative stress that can otherwise enhance the infective process

Nonspecific immunopotentiation and improvement of the vaccination effect

Mucolytic effect of vitamin $\mathrm{C}$ and possible alteration of bacteria cell surface qualities

[Geriatric Care 2021; 7:9338] 
virus (HIV) or hepatitis $\mathrm{C}$ virus. The role of zinc as an antiviral can be separated into two categories: i) zinc supplementation implemented to improve the antiviral response and systemic immunity in patients with zinc deficiency; and ii) zinc treatment performed to specifically inhibit viral replication or infection-related symptoms (Table 2). ${ }^{25}$ Zinc possess broad-spectrum antimicrobial activity. Among all viruses, HSV, SARS-CoV, transmissible gastroenteritis virus, HIV, vaccinia virus, equine arteritis virus, respiratory syncytial virus and rhinovirus are the viruses that are inhibited by zinc salts. The antiviral effects of zinc on viruses are mediated through different mechanisms, such as by inhibition of entry of viruses, by blocking polyprotein processing, or by inhibiting RNA-dependent RNA polymerase activity of the virus. In hepatitis E, zinc salts show their action by inhibiting the activity of HEV RNA-dependent RNA polymerase and also act by inhibiting RNA viral replication in HEV-infected cells. ${ }^{26}$ Oral zinc might show a reduction in the length and severity of a cold. ${ }^{27}$ Although the exact mechanism of action is unknown, there is some consensus that zinc in ionized form affects picornaviruses (rhinoviruses are viruses that cause the common cold, are from the family of Picornaviruses). ${ }^{28}$ Pyrithione (PT) is a zinc ionophore that frequently exists as a centrosymmetric dimmer to chelate $\mathrm{Zn} 2+$ ion via oxygen and sulfur centers. PT, which was used as an antibacterial and antifungal agent, has also shown effectiveness in inhibition of infections by several RNA viruses, such as coxsackievirus, human rhinovirus, ang mengovirus(these viruses belong to Picornaviridae family). PT can also efficiently inhibit the replication of a variety of RNA viruses. ${ }^{12}$ PT showed potent inhibitory effect against HSV-1 and HSV-2 infections. It was revealed that PT inhibited ICP4 gene expression and as a result caused the silence of viral early and late genes expression, leading to a reduction in producing viral progeny. It was also found that PT treatment also interferes with the cellular ubiquitinproteasome system. ${ }^{29}$

\section{Role of vitamin $C$ and zinc in COVID-19}

There is evidence that supports the protective effect of high dose IVC (HDIVC) during sepsis-induced ARDS. Vitamin C can transcriptionally upregulate the protein channels $(\mathrm{Na}+/ \mathrm{K}+$ ATPase, CFTR, aquaporin-5, and $\mathrm{ENaC}$ ) regulating the alveolar fluid clearance. ${ }^{30}$ HDIVC has been involved in reducing the formation of plasma cell-free DNA that is formed from the neutrophil extracellular trap, which facilitates systemic inflammation in multiple organ failure in sepsis. ${ }^{31}$ Interestingly, HDIVC significantly reduces syndecan-1, an endothelial glycocalyx, elevated levels of which in plasma corresponds with an increase in mortality in severe sepsis. ${ }^{31}$ According to randomized controlled trials undertaken at Zhongnan Hospital (NCT04264533) on 14 February 2020 that focuses on assessing the efficacy and safety of vitamin $\mathrm{C}$ in pneumonia caused by SARS-CoV-2. They hypothesize that IVC can improve the prognosis of acute respiratory infections. The treatment comprises $12 \mathrm{~g}$ vitamin $\mathrm{C}$ infusion ( $\mathrm{q} 12 \mathrm{~h}$ ) for seven days, and the outcome calculates the ventilator-free days. Its completion time is estimated in September 2020.5 Epithelial cells of lungs use oxidative phosphorylation in mitochondria to produce ATP, and effector cells of the immune system depends on glycolysis for bioenergetic functions. Therefore, high-dose vitamin $\mathrm{C}$ treatment acts as epithelial cells of lungs and prooxidant for immune effector cells. Additionally, treatment with vitamin $\mathrm{C}$ may also protect innate immunity of alveolar type II by inhibiting lactate secretion, produced by activated immune cells. In association with the prooxidant role of vitamin $\mathrm{C}$, which requires millimolar (pharmacological) rather than micromolar (physiological) concentrations, reevaluating the infusion of high dose vitamin $\mathrm{C}$ could be a timely choice for ARDS related to COVID-19. ${ }^{14}$ Moreover, a recent review, speculates the importance of nutrition as a mitigation strategy to support

Table 2. Antiviral effect zinc against viral infection. ${ }^{25}$

\begin{tabular}{|c|c|c|}
\hline Viral infection/condition & Antiviral effect & Effective dose \\
\hline Torque teno virus & Reduced viral load following stem cell transplant & $600 \mathrm{mg} \mathrm{ZnSO} / \mathrm{d}$ \\
\hline Herpes simplex & $\begin{array}{l}\text { Reduced duration and severity of the outbreak } \\
\text { Reduction in outbreak recurrence }\end{array}$ & $\begin{array}{l}\mathrm{ZnO} / \text { glycine cream }(0.3 \% \text { ionic } \mathrm{Zn}) \\
0.025 \% \mathrm{ZnSO} \text { solution }\end{array}$ \\
\hline Experimental rhinovirus & Reduced duration of illness with Zn(Glu)2 only & Zn(Glu)2 (13.3 mg) or Zn(OAc)2 (5/11.5 mg) lozenges, every 2-3 h/d \\
\hline Common cold & $\begin{array}{l}\text { Reduced symptom severity, frequency, and duration } \\
\text { Reduced symptom severity, frequency, and duration } \\
\text { Reduced duration of symptoms } \\
\text { Reduced symptom severity and duration }\end{array}$ & $\begin{array}{l}\text { ZGG lozenges containing } 23 \mathrm{mg} \text { Zn, every } 2 \mathrm{~h} / \mathrm{d} \\
\text { ZGG lozenges containing } 24 \mathrm{mg} \mathrm{Zn} \text {, every } 2-3 \mathrm{~h} / \mathrm{d} \\
\text { ZGG lozenges containing } 13 \mathrm{mg} \mathrm{Zn} \text {, every } 2 \mathrm{~h} / \mathrm{d} \\
\mathrm{Zn}(\mathrm{OAc}) 2 \text { lozenges each containing } 9 \mathrm{mg} \mathrm{Zn} \text {, every } 2 \mathrm{~h} / \mathrm{d}\end{array}$ \\
\hline Viral warts & $\begin{array}{l}\text { Improved clearance of warts after } 1-2 \mathrm{mo} \\
\text { Removal of warts based on the concentration of zinc used } \\
\text { Enhanced clearance of warts after } 1-2 \mathrm{mo} \\
\text { No benefit } \\
\text { Resolution of } 88 \% \text { lesions after } 6 \mathrm{wk} / 3 \text { sessions }\end{array}$ & $\begin{array}{l}10 \mathrm{mg} / \mathrm{kg} \mathrm{ZnSO4} \text { to a maximum dose of } 600 \mathrm{mg} / \mathrm{d} \\
3 \times 5 \mathrm{or} 10 \% \mathrm{ZnSO} / \mathrm{d} \\
10 \mathrm{mg} / \mathrm{kg} \mathrm{ZnSO} 4 \text { to a maximum dose of } 600 \mathrm{mg} / \mathrm{d} \\
10 \mathrm{mg} / \mathrm{kg} \mathrm{ZnSO} / \mathrm{d} \\
\text { Up to } 3 \text { intralesional injections with } 2 \% \mathrm{ZnSO} 4 \text { injection }\end{array}$ \\
\hline Laryngeal papillomatosis & Resolution of papillomatosis (2 case studies) & $10 \mathrm{mg} / \mathrm{kg} \mathrm{ZnSO} / \mathrm{d}$ \\
\hline HIV & $\begin{array}{l}\text { Reduced infection, increased CD4 T cell count } \\
\text { Increased CD4 T cell count } \\
\text { Reduced incidence of diarrhea } \\
\text { No benefit }\end{array}$ & $\begin{array}{l}200 \mathrm{mg} / \mathrm{dZnSO} 4 / \mathrm{d} \\
45 \mathrm{mg} \mathrm{Zn(Glu}) 2 \text { every } 8 \mathrm{~h} \text { for } 15 \mathrm{~d} \text {, then } 15 \mathrm{mg} \text { for } 15 \mathrm{~d} \\
10 \mathrm{mg} \text { elemental zinc as ZnSO4/d } \\
25 \mathrm{mg} / \mathrm{dZnSO4/ \textrm {d }}\end{array}$ \\
\hline Chronic hepatitis C virus & $\begin{array}{l}\text { Enhanced response to IFN treatment } \\
\text { No benefit to IFN treatment response } \\
\text { Reduced serum ALT, AST and ferritin } \\
\text { Reduced serum ALT and Th2 cells } \\
\text { Reduced incidence of HCC (albumin dependent) }\end{array}$ & $\begin{array}{l}2 \times 75 \mathrm{mg} \text { polapre zinc/d } \\
5 \times 78 \mathrm{mg} \text { An }(\mathrm{Glu}) 2 / \mathrm{d} \\
3 \times 75 \mathrm{mg} \text { polaprezinc } / \mathrm{d} \\
2 \times 75 \mathrm{mg} \text { polaprezinc } / \mathrm{d} \\
2 \times 150 \mathrm{mg} \text { polaprezinc } / \mathrm{d}\end{array}$ \\
\hline
\end{tabular}

IFN, interferon; ALT, alanine aminotransferase; AST, aspartate aminotransferase, HCC, hepatocellular carcinoma. 
immune function amid the COVID-19 pandemic, identifying food groups and key nutrients of importance that may affect the outcomes of respiratory infections. ${ }^{32}$

Zinc might be one of the trace elements that could reduce respiratory tract infections due to antiviral properties and may lessen the intensity of COVID-19. ${ }^{33}$ The combination of PT and zinc inhibit SARS-CoV replication at a lower concentration. Therefore, zinc affects not only on symptoms related to COVID-19 like lower respiratory tract infections and diarrhea but also affects COVID-19 itself. ${ }^{20}$ Disulfiram (zinc ejector drug) can serve as a multi-target drug by acting at various life cycle stages of virus: It inhibits replication of COVID-19 by targeting Zn-binding cysteines in Papain-like cysteine protease (PLpro), nsp13 and nsp10, and catalytic cysteines in cysteine proteases (PLpro and 3CLpro) that catalyze polyprotein cleavage. Hence it might exhibit a barrier to COVID-19 resistance higher than other antiviral agents by targeting essential cysteines in multiple domains, as Zn-bound/catalytic cysteines mutation would render the virus unable to survive. ${ }^{7}$ Moreover, consumption of 25-50 $\mathrm{mg}$ of zinc per day is less likely to induce toxicity, but $>200-400 \mathrm{mg}$ per day can cause adverse effects like vomiting, nausea, epigastric pain, fatigue, and lethargy. ${ }^{33}$

\section{Conclusions}

This study is not experimental, which is its most significant limitation. As of now, there is no vaccine or defined protocol for the management of patients suffering from coronavirus disease, so people must maintain good hygiene and social distance, both of which will prevent the spread of COVID19. Along with these, it is of paramount importance that the population takes measures that help in boosting or maintaining an immune response, so in case people get infected, they don't become severely sick rapidly. Vitamin C, a water-soluble vitamin, has antioxidant properties, and its level is found to be reduced in the patient's infected pulmonary viral infections. Apart from it, deficiency of vitamin $\mathrm{C}$ is also associated with abnormal collagen formation, which can lead to poor wound healing and oral disease like scurvy.

Zinc possesses a broad spectrum of antimicrobial activity, and it may inhibit the activity of coronavirus by preventing entry into the host cells or by inhibiting RNA dependent RNA polymerase. Zinc supplementation also may shorten the duration of the disease.

\section{References}

1. Haq FU, Roman M, Ahmad K, et al. Artemisia annua: trials are needed for COVID-19. Phytother Res 2020 [Epub ahead of print].

2. Haq FU, Khan MU, Muazzam A, et al. Interferon- $\beta$ : treatment option against COVID-19. Geriatric Care 2020 [Epub ahead of print].

3. Khan MU, Muazzam A, Farooq H, et al. Interferon- $\beta$ : treatment option against COVID-19. Geriatric Care 2020;6:9093.

4. Wimalawansa SJ. Global epidemic of coronavirus - COVID-19: what can we do to minimize risks. Eur J Biomed 2020;7:432-8.

5. Kakodkar P, Kaka N, Baig M. A comprehensive literature review on the clinical presentation, and management of the pandemic coronavirus disease 2019 (COVID-19). Cureus 2020;12:4.

6. World Health Organization. Coronavirus disease (COVID-19): situation report, 150; 2020. Retrieved on 20 June 2020. https://www.who.int/emergencies/diseases/novel-coronavirus-2019/situationreports

7. Sargsyan K, Chen T, Grauffel C, Lim C. Targeting 2019 novel coronavirus with clinically safe Zn-ejector drugs. Preprints 2020 [Epub ahead of print].

8. Coleman CM, Frieman MB. Coronaviruses: important emerging human pathogens. J Virol 2014;88:5209-12.

9. Romero-Sánchez CM, Díaz-Maroto I, Fernández-Díaz E, et al. Neurologic manifestations in hospitalized patients with COVID-19: The ALBACOVID registry. Neurology 2020 [Epub ahead of print].

10. Wu Y, Xu X, Chen Z, et al. Nervous system involvement after infection with COVID-19 and other coronaviruses. Brain Behav Immun 2020 [Epub ahead of print].

11. Ye M, Ren Y, Lv T. Encephalitis as a clinical manifestation of COVID-19. Brain Behav Immun 2020 [Epub ahead of print].

12. Zhang L, Liu Y. Potential interventions for novel coronavirus in China: a systemic review. J Med Virol 2020 [Epub ahead of print].

13. Colunga Biancatelli RML, Berrill M, Marik PE. The antiviral properties of vitamin C. New York: Taylor \& Francis; 2020.

14. Erol A. High-dose intravenous vitamin C treatment for COVID-19. Preprints 2020 [Epub ahead of print].

15. Wintergerst ES, Maggini S, Hornig DH. Immune-enhancing role of vitamin $\mathrm{C}$ and zinc and effect on clinical conditions. Ann Nutr Metab 2006;50:85-94.

16. Ewer T, Lewis G. Intravenous vitamin C and the treatment of infections. J Austral Coll Nutr Environ Med 2011;30:8.
17. Carr AC, Maggini S. Vitamin $C$ and immune function. Nutrients 2017; 9:1211.

18. Englard S, Seifter S. The biochemical functions of ascorbic acid. Annu Rev Nutr 1986;6:365-406.

19. Mandl J, Szarka A, Banhegyi G. Vitamin C: update on physiology and pharmacology. Br J Pharmacol 2009;157:1097-110.

20. Zhang L, Liu Y. Potential interventions for novel coronavirus in China: A systematic review. J Med Virol 2020;92: 479-90.

21. Mikirova NA, Hunninghake R. Effect of high dose vitamin $\mathrm{C}$ on Epstein-Barr viral infection. Med Sci Monitor 2014; 20:725.

22. Biancatelli RC, Berrill M, Marik PE. The antiviral properties of vitamin C. Exp Rev Anti-Infect Ther 2020;18:99-101.

23. Kim G-N, Yoo W-S, Park M-H, et al. Clinical features of herpes simplex keratitis in a Korean tertiary referral center: efficacy of oral antiviral and ascorbic acid on recurrence. Korean J Ophthalmol 2018;32:353-60

24. Byun SH, Jeon Y. Administration of vitamin $\mathrm{C}$ in a patient with herpes zoster-a case report. Korean J Pain 2011;24:108.

25. Read SA, Obeid S, Ahlenstiel C, Ahlenstiel G. The role of zinc in antiviral immunity. Adv Nutr 2019;10:696-710.

26. Kaushik N, Subramani C, Anang S, et al. Zinc salts block hepatitis E virus replication by inhibiting the activity of viral RNA-dependent RNA polymerase. J Virol 2017;91:21.

27. Mousa HA-L. Prevention and treatment of influenza, influenza-like illness, and common cold by herbal, complementary, and natural therapies. J Evid-Based Complement Alternat Med 2017;22: 166-74.

28. Singh M, Das RR. Clinical potential of zinc in prophylaxis of the common cold. Exp Rev Respir Med 2011;5:301-3.

29. Qiu M, Chen Y, Chu Y, et al. Zinc ionophores pyrithione inhibits herpes simplex virus replication through interfering with proteasome function and NF$\kappa \mathrm{B}$ activation. Antiviral Res 2013;100: 44-53.

30. Rodrigues da Silva M, Schapochnik A, Peres Leal M, et al. Beneficial effects of ascorbic acid to treat lung fibrosis induced by paraquat. PLoS One 2018;13:e0205535.

31. Kashiouris MG, L'Heureux M, Cable $\mathrm{CA}$, et al. The emerging role of vitamin $\mathrm{C}$ as a treatment for sepsis. Nutrients 2020;12:292.

32. Zabetakis I, Lordan R, Norton C, Tsoupras A. COVID-19: the inflammation link and the role of nutrition in potential mitigation. Nutrients 2020; 12:1466.

33. Razzaque M. COVID-19 pandemic: Can maintaining optimal zinc balance enhance host resistance? Preprints 2020 [Epub ahead of print]. 